\title{
Plasma and Cerebrospinal Fluid Pharmacokinetics of Thalidomide and Lenalidomide in Nonhuman Primates
}

\author{
Jodi A. Muscal ${ }^{1}$, Yongkai Sun², Jed G. Nuchtern ${ }^{3}$, Robert C. Dauser ${ }^{4}$, Leticia H. McGuffey ${ }^{1}$, \\ Brian W. Gibson ${ }^{5}$, and Stacey L. Berg ${ }^{1}$ \\ ${ }^{1}$ Texas Children's Cancer Center, Baylor College of Medicine, Houston, TX, USA \\ ${ }^{2}$ Celgene Corporation, Summit, NJ, USA \\ ${ }^{3}$ Department of Surgery, Texas Children's Hospital, Baylor College of Medicine, Houston, TX, \\ USA \\ ${ }^{4}$ Department of Neurosurgery, Texas Children's Hospital, Baylor College of Medicine, Houston, \\ TX, USA \\ ${ }^{5}$ Center for Comparative Medicine, Baylor College of Medicine, Houston, TX, USA
}

\begin{abstract}
Purpose-Thalidomide, originally developed as a sedative, was subsequently identified to have antiangiogenic properties. Lenalidomide is an antiangiogenic and immunomodulatory agent that has been utilized in the treatment of patients with brain tumors. We studied the pharmacokinetics and cerebrospinal fluid (CSF) penetration of thalidomide and lenalidomide in a nonhuman primate model.
\end{abstract}

\begin{abstract}
Methods-A dose of $50 \mathrm{mg}$ of thalidomide or $20 \mathrm{mg}$ of lenalidomide were administered once orally to each of three rhesus monkeys. Plasma and CSF samples were obtained at specified intervals and the thalidomide or lenalidomide concentrations were determined by highperformance liquid chromatography with tandem mass spectrometry. Pharmacokinetic parameters were estimated using noncompartmental methods. CSF penetration was calculated as area under the concentration-time curve (AUC) CSF/AUC plasma.
\end{abstract}

Results-For thalidomide, the median apparent clearance $(\mathrm{Cl} / \mathrm{F})$ was $2.9 \mathrm{~mL} / \mathrm{min} / \mathrm{kg}$, the median plasma AUC was $80 \mu \mathrm{M} \bullet \mathrm{hr}$, and the median terminal half-life ( $\left.\mathrm{t}_{1 / 2}\right)$ was 13.3 hours. For lenalidomide, the median $\mathrm{Cl} / \mathrm{F}$ was $8.7 \mathrm{~mL} / \mathrm{min} / \mathrm{kg}$, the median AUC was $9 \mu \mathrm{M} \bullet \mathrm{hr}$, and the median $\mathrm{t}_{1 / 2}$ was 5.6 hours. Thalidomide was detected in the CSF of all animals, with a median penetration of $42 \%$. Lenalidomide was detected in the CSF of 2 of 3 animals, with a CSF penetration of $11 \%$ in each.

Conclusion-Thalidomide and lenalidomide penetrate into the CSF after oral administration of clinically relevant doses. Plasma exposure to lenalidomide was similar in our model to that observed in studies involving children who have brain tumors. These results support further development of lenalidomide for the treatment of central nervous system malignancies.

\section{Keywords}

thalidomide; lenalidomide; pharmacokinetics; CSF penetration; nonhuman primates

Corresponding author: Stacey Berg, Texas Children's Cancer Center, 1102 Bates Street, Suite 1220, Houston, TX, 77030. Phone: 832-824-4588; Fax: 832-825-4039, sberg@ $@$ txch.org. 


\section{INTRODUCTION}

Central nervous system (CNS) tumors are the most common solid tumor in children, comprising $25 \%$ of all childhood cancers [1]. Overall survival for children with brain tumors is approximately $75 \%$ [2]; however, children with high-grade gliomas and diffuse intrinsic pontine gliomas fare poorly $[3,4]$. Similarly, children whose cancer metastasizes to the CNS often have poor outcomes. Therefore, new drugs are needed for malignant childhood brain tumors.

Initially withdrawn from the market due to teratogenic effects of the drug, thalidomide was approved in 1998 by the US Food and Drug Administration (FDA) for the management of erythema nodosum leprosum [5]. Further investigation of thalidomide characterized its antiangiogenic and immunomodulatory effects [6]. Lenalidomide (CC-5013, Revlimid ${ }^{\circledR}$ brand drug: Celgene Corporation, Summit, NJ) is a compound with enhanced immunomodulatory potency and decreased sedative and neurotoxic properties [7]. It is approved by the FDA for the treatment of adults with transfusion-dependent del(5q) myelodysplastic syndrome and, in combination with dexamethasone, for the treatment of multiple myeloma [8].

The mechanism of action directly responsible for lenalidomide's anti-tumor activity is not known. It inhibits the secretion of pro-inflammatory cytokines [9]; increases the secretion of anti-inflammatory cytokines [9]; induces T-cell proliferation [10] and interleukin-2 and interferon- $\gamma$ production [11]; suppresses endothelial response to angiogenic molecules [12]; and promotes G1 cell cycle arrest and apoptosis of malignant cells [13]. Since tumor growth is believed to be partly dependent on the ability of a tumor to neovascularize, angiogenesis inhibitors may play a role in the prevention of tumor growth or decrease the risk for tumor metastases. Lenalidomide has been well-tolerated in adults and children with recurrent CNS tumors [14-16]. The CNS penetration of thalidomide and lenalidomide remains unknown, and this information is important to determine potential tumor targets for this class of drugs, including their use in leptomeningeal disease. Thus we studied the cerebrospinal (CSF) penetration of thalidomide and lenalidomide in a nonhuman primate model that has been highly predictive of anticancer drug distribution in humans [17].

\section{MATERIALS AND METHODS}

\section{Drug}

Thalidomide and lenalidomide were supplied by Celgene Corporation (Summit, NJ) as a powder. Thalidomide $50 \mathrm{mg}$ was diluted in $6.5 \mathrm{~mL} 1 \%$ carboxymethylcellulose and lenalidomide $20 \mathrm{mg}$ was diluted in $2.5 \mathrm{~mL} 1 \%$ carboxymethylcellulose before oral administration.

\section{Animals}

Four adult male rhesus monkeys (Macaca mulatta) weighing 10 to $16.8 \mathrm{~kg}$ were used in these experiments, which were approved by the Institutional Animal Care and Use Committee. The animals were fed Purina Lab Diet 5045 High Protein Monkey Diet twice daily and housed in accordance with Guide for the Care and Use of Laboratory Animals [18]. Drug was given orally. Blood samples were drawn through a catheter placed in the saphenous vein. Ventricular CSF samples were obtained from a chronically indwelling fourth ventricular catheter attached to a subcutaneously implanted Ommaya reservoir [17]. 


\section{Experiments}

Thalidomide $50 \mathrm{mg}(3.2-3.6 \mathrm{mg} / \mathrm{kg})$ or lenalidomide $20 \mathrm{mg}(1.2-2 \mathrm{mg} / \mathrm{kg})$ were administered once orally to three animals. Blood and ventricular CSF were collected immediately before the dose and at 30, 60, 90 minutes, and 2, 3, 4, 6, 8, 10, and 24 hours after the drug was administered. Plasma was separated immediately by centrifugation at $1,500 \mathrm{rpm}$ for ten minutes. Plasma and CSF were frozen immediately after collection and diluted 1:1 with Sorensen's citrate buffer $(\mathrm{pH} 1.5$; prepared by combining $70 \mathrm{~mL} 0.1 \mathrm{M}$ citric acid, $5 \mathrm{~mL} 0.1 \mathrm{M}$ sodium citrate dihydrate, and $425 \mathrm{~mL}$ water, and adjusting the $\mathrm{pH}$ with concentrated $\mathrm{HCl}$ ) and stored at $\leq-60^{\circ} \mathrm{C}$ until analysis. Clinical laboratory studies including complete blood counts, electrolytes, liver function tests, and renal function tests were obtained on a weekly basis for a minimum of three weeks after drug administration. Animals were also observed on a daily basis for a minimum of three weeks after drug administration for any evidence of clinical toxicity.

\section{Sample analysis}

The calibration standard and quality control samples were prepared in artificial CSF (aCSF) (Online Resource 1) or rhesus monkey plasma (Bioreclamation, Hicksville, NY) mixed (1:1, v/v) with Sorensen's citrate buffer. ${ }^{13} \mathrm{C}_{5}$-lenalidomide (synthesized by Celgene Corporation) and thalidomide- $\mathrm{d}_{4}$ (Toronto Research Chemicals, North York, ON, Canada) in methanol were used as internal standards. The text has been update to include the following: The analytical dynamic ranges for lenalidomide and thalidomide are 3.82-1928 $\mu \mathrm{M}$ and 18.82$3872 \mu \mathrm{M}$, respectively. Three levels of quality controls were included in each run (Online Resource 2).

For CSF analysis, $80 \mu \mathrm{L}$ of each thawed sample was mixed with $20 \mu \mathrm{L}$ of internal standard working solution. Then samples were vortexed and centrifuged at 2,000 rpm for three minutes before being injected into the high performance liquid chromatography (HPLC)tandem mass spectrometry system for analysis. For plasma analysis, $100 \mu \mathrm{L}$ of each thawed sample was mixed with $300 \mu \mathrm{L}$ of internal standard working solution to precipitate proteins. Then samples were vortexed and centrifuged at 3,500 rpm for 15 minutes. The supernatants ( $350 \mu \mathrm{L}$ per sample) were transferred and mixed with $40 \mu \mathrm{L}$ of methanol containing $5 \%$ formic acid, then evaporated to dryness under $\mathrm{N}_{2}$ at $35^{\circ} \mathrm{C}$ and reconstituted into $100 \mu \mathrm{L}$ of water/acetonitrile/formic acid (80:20:0.4), for lenalidomide or water/methanol/formic acid (50:50:0.1), for thalidomide. For each sample, $10 \mu \mathrm{L}$ of sample was injected onto a HPLC system consisting of Shimadzu LC-20ADXR UFLC pumps with Shimadzu SIL-20ACXR autosampler (Shimadzu, Shanghai, China) using a Phenomenex Luna C18 (2) column (50 $\times$ $2.0 \mathrm{~mm}, 5 \mu \mathrm{m}$ ) (Torrance, CA). The mobile phase consisted of $0.1 \%$ formic acid in water (mobile phase A) and $0.1 \%$ formic acid in acetonitrile (mobile phase B) at a flow rate of 0.4 $\mathrm{mL} /$ minute. A gradient elution was performed at 5-30\% mobile phase B from 0 to 1 minute, $30-95 \%$ B from 1 to 2 minutes, 95\% B from 2 to 2.5 minutes, and 5\% B from 2.6 to 4 minutes. Compounds were detected using an API4000 QTrap mass spectrometer (Ontario, Canada).

\section{Pharmacokinetic analysis}

Noncompartmental methods were employed to derive the pharmacokinetic parameters. Terminal half-lives $\left(t_{1 / 2}\right)$ were estimated using first order kinetics. For both plasma and CSF, the areas under the concentration-time curve (AUC) were determined by the linear trapezoidal method to the last measured concentration $\left(\mathrm{AUC}_{\text {last }}\right)$ and extrapolated to infinity $\left(\mathrm{AUC}_{\text {inf }}\right)$ using the terminal rate constant [19]. CSF penetration was calculated as $\mathrm{AUC}_{\text {inf }}$ $\mathrm{CSF} / \mathrm{AUC}_{\text {inf }}$ plasma. 


\section{RESULTS}

Pharmacokinetic parameters after oral administration of thalidomide and lenalidomide are presented in Tables 1 and 2. For thalidomide, the median apparent clearance $(\mathrm{Cl} / \mathrm{F})$ was 2.9 $\mathrm{mL} / \mathrm{min} / \mathrm{kg}$ (range, 2.6-3.6), median plasma $\mathrm{AUC}_{\text {inf }}$ was $80 \mu \mathrm{M} \bullet \mathrm{hr}$ (range, 80-88), and the median plasma $\mathrm{t}_{1 / 2}$ was 13.3 hours (range, 8.1-13.7). For lenalidomide, the median $\mathrm{Cl} / \mathrm{F}$ was $8.7 \mathrm{~mL} / \mathrm{min} / \mathrm{kg}$ (range, 6.6-18.7), the median plasma $\mathrm{AUC}_{\text {inf }}$ was $9 \mu \mathrm{M} \bullet \mathrm{hr}$ (range, 7-13), and the median plasma $\mathrm{t}_{1 / 2}$ was 5.6 hours (range, 4.4-8.2). For thalidomide, the median CSF $\mathrm{AUC}_{\text {inf }}$ was $33 \mu \mathrm{M} \bullet \mathrm{hr}$ (range, 32-40), and the median CSF penetration was $42 \%$ (range, 3650). For lenalidomide, drug was detected in the CSF of 2 of the 3 animals. The CSF AUC was 1.0 and $1.4 \mu \mathrm{M} \bullet \mathrm{hr}$, and in both animals, the CSF penetration was $11 \%$. Mean plasma and CSF concentrations for thalidomide (Figure 1) and lenalidomide (Figure 2) are shown. The animals tolerated the drugs without significant clinical or laboratory toxicity.

\section{DISCUSSION}

Thalidomide and lenalidomide have both been used successfully in the treatment of malignancies, especially myelodysplastic diseases. The CNS penetration of these agents is of interest because thalidomide has prominent CNS toxicity, i.e., sedation [20], while lenalidomide has shown some activity in patients with brain tumors [21]. While both of these agents have been studied in children [16, 21, 22], their CSF penetration has not been described in detail. In this study, we demonstrated that there was notable CNS penetration of thalidomide (42\%) and lenalidomide (11\%) following oral dosing in the nonhuman primate. This degree of penetration compares well to that of standard chemotherapy drugs commonly used for systemic treatment of leptomeningeal disease, such as cytarabine, methotrexate, and corticosteroids, whose CNS penetration ranges from 3-20\% [23].

In our study, the $50 \mathrm{mg}$ dose of thalidomide given to the nonhuman primates is comparable to a dose of approximately $65-100 \mathrm{mg} / \mathrm{m}^{2}$ in humans. The median $\mathrm{Cl} / \mathrm{F}$ of thalidomide (59 $\mathrm{mL} / \mathrm{min} / \mathrm{m}^{2}$ ) was very similar to that seen in children $\left(55 \mathrm{~mL} / \mathrm{min} / \mathrm{m}^{2}\right)$ [22] and adults ( 85 $\mathrm{mL} / \mathrm{min} / \mathrm{m}^{2}$ ) [24]. The $\mathrm{t}_{1 / 2}$ was also similar, with a mean of approximately 13 hours in the primates, 6 hours in children [22], and 5-6 hours in adults [24, 25, 26, 27].

The $20 \mathrm{mg}$ dose of lenalidomide used in our study compares to approximately $25-40 \mathrm{mg} / \mathrm{m}^{2}$ in humans. The $\mathrm{Cl} / \mathrm{F}$ of lenalidomide $\left(174 \mathrm{~mL} / \mathrm{min} / \mathrm{m}^{2}\right)$ is higher than the $\mathrm{Cl} / \mathrm{F}$ of thalidomide $\left(59 \mathrm{~mL} / \mathrm{min} / \mathrm{m}^{2}\right)$, and comparable to that of lenalidomide in adults $(116 \mathrm{~mL} /$ $\left.\mathrm{min} / \mathrm{m}^{2}\right)$ [28] and children $\left(136-234 \mathrm{~mL} / \mathrm{min} / \mathrm{m}^{2}\right)$ [16, 21]. Also, the $\mathrm{t}_{1 / 2}$ of 5.6 hours for lenalidomide in non-human primates is slightly longer than that of approximately 2.5 hours in children [16, 21] and 4 hours in adults [28].

In our study, thalidomide exhibited higher CSF penetration (42\%) than lenalidomide (11\%). In the phase I clinical trial of thalidomide, $20 \%$ of children who received thalidomide experienced somnolence [22]. In contrast, somnolence was not reported in either phase I study of lenalidomide in children $[16,21]$ nor in the phase I study of lenalidomide in adults with CNS tumors [15]. It is not known whether the increased CSF exposure of thalidomide compared with lenalidomide is related to the difference in side effect profile observed between the two drugs.

Clinical responses to lenalidomide have been observed in children with CNS tumors. In the study by Warren and colleagues, out of 47 patients evaluable for response, there were two partial responses and 23 patients with stable disease $>6$ months [21]. Although we observed moderate CSF penetration of lenalidomide in 2 of the 3 animals, lenalidomide was below the limit of quantitation in the third. It is likely that CNS penetration is better in tumors that have a disrupted blood-brain barrier compared with the intact blood-brain barrier in our 
model. Taken together, our data support the further evaluation of lenalidomide in patients with CNS tumors.

\section{Supplementary Material}

Refer to Web version on PubMed Central for supplementary material.

\section{Acknowledgments}

\section{GRANT SUPPORT}

Grant support: National Cancer Institute K12 Pediatric Clinical Oncology Research Training Program 5K12CA90433-09 (JA Muscal)

\section{REFERENCES}

1. Arora RS, Alston RD, Eden TO, Estlin EJ, Moran A, Birch JM. Age-incidence patterns of primary CNS tumors in children, adolescents, and adults in England. Neuro Oncol. 2009; 11(4):403-413. [PubMed: 19033157]

2. Jemal A, Siegel R, Ward E, Hao Y, Xu J, Murray T, Thun MJ. Cancer statistics, 2008. CA Cancer J Clin. 2008; 58(2):71-96. [PubMed: 18287387]

3. Wisoff JH, Boyett JM, Berger MS, Brant C, Li H, Yates AJ, McGuire-Cullen P, Turski PA, Sutton LN, Allen JC, Packer RJ, Finlay JL. Current neurosurgical management and the impact of the extent of resection in the treatment of malignant gliomas of childhood: a report of the Children's Cancer Group trial no. CCG-945. J Neurosurg. 1998; 89(1):52-59. [PubMed: 9647172]

4. Freeman CR, Kepner J, Kun LE, Sanford RA, Kadota R, Mandell L, Friedman H. A detrimental effect of a combined chemotherapy-radiotherapy approach in children with diffuse intrinsic brain stem gliomas? Int J Radiat Oncol Biol Phys. 2000; 47((3)):561-564. [PubMed: 10837936]

5. Nightingale SL. From the Food and Drug Administration. JAMA. 1998; 280(10):872. [PubMed: 9739956]

6. List AF. Lenalidomide--the phoenix rises. New Engl J Med. 2007; 357(21):2183-2186. [PubMed: 18032768]

7. Melchert M, List A. The thalidomide saga. Int J Biochem Cell Biol. 2007; 39(7-8):1489-1499. [PubMed: 17369076]

8. Palumbo A, Dimopoulos M, San Miguel J, Harousseau JL, Attal M, Hussein M, Knop S, Ludwig H, von Lilienfeld-Toal M, Sonneveld P. Lenalidomide in combination with dexamethasone for the treatment of relapsed or refractory multiple myeloma. Blood Rev. 2009; 23(2):87-93. [PubMed: 18774632]

9. Corral LG, Haslett PA, Muller GW, Chen R, Wong LM, Ocampo CJ, Patterson RT, Stirling DI, Kaplan G. Differential cytokine modulation and T cell activation by two distinct classes of thalidomide analogues that are potent inhibitors of TNF-alpha. J Immunol. 1999; 163(1):380-386. [PubMed: 10384139]

10. Haslett PA, Corral LG, Albert M, Kaplan G. Thalidomide costimulates primary human T lymphocytes, preferentially inducing proliferation, cytokine production, and cytotoxic responses in the CD8+ subset. J Exp Med. 1998; 187(11):1885-1892. [PubMed: 9607928]

11. McHugh SM, Rifkin IR, Deighton J, Wilson AB, Lachmann PJ, Lockwood CM, Ewan PW. The immunosuppressive drug thalidomide induces T helper cell type $2(\mathrm{Th} 2)$ and concomitantly inhibits Th1 cytokine production in mitogen- and antigen-stimulated human peripheral blood mononuclear cell cultures. Clin Exp Immunol. 1995; 99(2):160-167. [PubMed: 7851006]

12. Dredge K, Horsfall R, Robinson SP, Zhang LH, Lu L, Tang Y, Shirley MA, Muller G, Schafer P, Stirling D, Dalgleish AG, Bartlett JB. Orally administered lenalidomide (CC-5013) is antiangiogenic in vivo and inhibits endothelial cell migration and Akt phosphorylation in vitro. Microvasc Res. 2005; 69(1-2):56-63. [PubMed: 15797261] 
13. Gandhi AK, Kang J, Naziruddin S, Parton A, Schafer PH, Stirling DI. Lenalidomide inhibits proliferation of Namalwa CSN.70 cells and interferes with Gab1 phosphorylation and adaptor protein complex assembly. Leuk Res. 2006; 30(7):849-858. [PubMed: 16494942]

14. Drappatz J, Wong ET, Schiff D, Kesari S, Batchelor TT, Doherty L, Lafrankie DC, Ramakrishna N, Weiss S, Smith ST, Ciampa A, Zimmerman J, Ostrowsky L, David K, Norden A, Barron L, Sceppa C, Black PM, Wen PY. A pilot safety study of lenalidomide and radiotherapy for patients with newly diagnosed glioblastoma multiforme. Int J Radiat Oncol Biol Phys. 2009; 73(1):222227. [PubMed: 18513880]

15. Fine HA, Kim L, Albert PS, Duic JP, Ma H, Zhang W, Tohnya T, Figg WD, Royce C. A phase I trial of lenalidomide in patients with recurrent primary central nervous system tumors. Clin Cancer Res. 2007; 13(23):7101-7106. [PubMed: 18056189]

16. Berg SL, Cairo MS, Russell H, Ayello J, Ingle AM, Lau H, Chen N, Adamson PC, Blaney SM. Safety, Pharmacokinetics, and Immunomodulatory Effects of Lenalidomide in Children and Adolescents With Relapsed/Refractory Solid Tumors or Myelodysplastic Syndrome: A Children's Oncology Group Phase I Consortium Report. J Clin Oncol. 2011; 29(3):316-323. [PubMed: 21149673]

17. McCully CL, Balis FM, Bacher J, Phillips J, Poplack DG. A rhesus monkey model for continuous infusion of drugs into cerebrospinal fluid. Lab Anim Sci. 1990; 40(5):520-525. [PubMed: 2170754]

18. National Research Council. Guide for the care and use of laboratory animals. Washington (DC): National Academy Press; 1996.

19. Gibladi, M.; Perrier, D. Phamacokinetics. 2nd ed.. York and Basel: Marcel Dekker, Inc; 1982.

20. Calabrese L, Fleischer AB. Thalidomide: current and potential clinical applications. Am J Med. 2000; 108(6):487-495. [PubMed: 10781782]

21. Warren KE, Goldman S, Pollack IF, Fangusaro J, Schaiquevich P, Stewart CF, Wallace D, Blaney SM, Packer R, Macdonald T, Jakacki R, Boyett JM, Kun LE. Phase I Trial of Lenalidomide in Pediatric Patients With Recurrent, Refractory, or Progressive Primary CNS Tumors: Pediatric Brain Tumor Consortium Study PBTC-018. J Clin Oncol. 2011; 29(3):324-329. [PubMed: 21149652]

22. Chintagumpala M, Blaney SM, Bomgaars LR, Aleksic A, Kuttesch JF, Klenke RA, Berg SL. Phase I and pharmacokinetic study of thalidomide with carboplatin in children with cancer. J Clin Oncol. 2004; 22(21):4394-4400. [PubMed: 15514381]

23. Berg SL, Chamberlain MC. Systemic chemotherapy, intrathecal chemotherapy, and symptom management in the treatment of leptomeningeal metastasis. Curr Oncol Rep. 2003; 5(1):29-40. [PubMed: 12493148]

24. Aweeka F, Trapnell C, Chernoff M, Jayewardene A, Spritzler J, Bellibas SE, Lizak P, Jacobson J. Pharmacokinetics and pharmacodynamics of thalidomide in HIV patients treated for oral aphthous ulcers: ACTG protocol 251. AIDS Clinical Trials Group. J Clin Pharmacol. 2001; 41(10):10911097. [PubMed: 11583477]

25. Figg WD, Raje S, Bauer KS, Tompkins A, Venzon D, Bergan R, Chen A, Hamilton M, Pluda J, Reed E. Pharmacokinetics of thalidomide in an elderly prostate cancer population. J Pharm Sci. 1999; 88(1):121-125. [PubMed: 9874712]

26. Piscitelli SC, Figg WD, Hahn B, Kelly G, Thomas S, Walker RE. Single-dose pharmacokinetics of thalidomide in human immunodeficiency virus-infected patients. Antimicrob Agents Chemother. 1997; 41(12):2797-2799. [PubMed: 9420064]

27. Noormohamed FH, Youle MS, Higgs CJ, Kook KA, Hawkins DA, Lant AF, Thomas SD. Pharmacokinetics and hemodynamic effects of single oral doses of thalidomide in asymptomatic human immunodeficiency virus-infected subjects. AIDS Res Hum Retroviruses. 1999; 15(12): 1047-1052. [PubMed: 10461824]

28. Blum W, Klisovic RB, Becker H, Yang X, Rozewski DM, Phelps MA, Garzon R, Walker A, Chandler JC, Whitman SP, Curfman J, Liu S, Schaaf L, Mickle J, Kefauver C, Devine SM, Grever MR, Marcucci G, Byrd JC. Dose escalation of lenalidomide in relapsed or refractory acute leukemias. J Clin Oncol. 2010; 28(33):4919-4925. [PubMed: 20956622] 


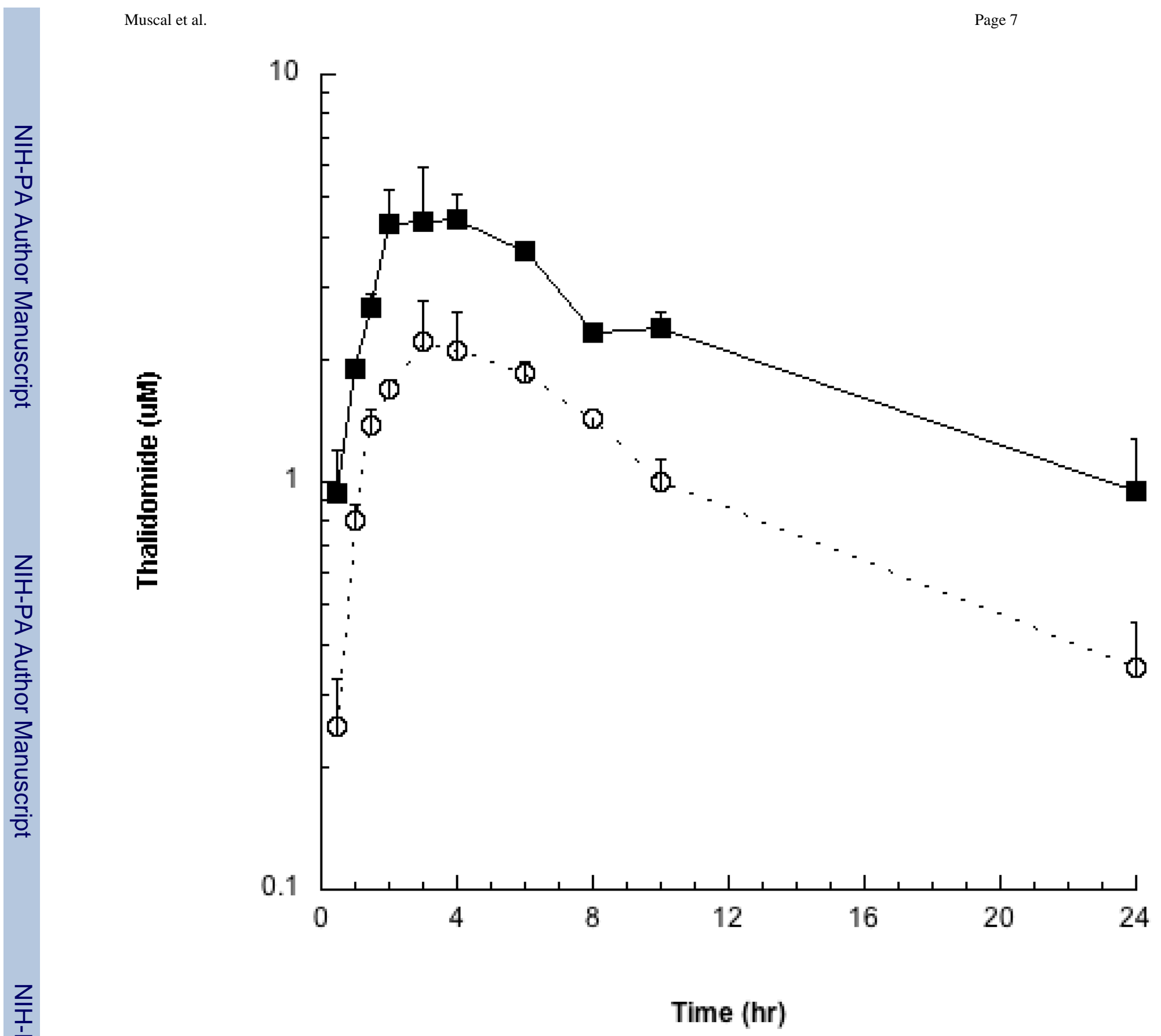

Fig. 1.

Mean plasma ( $\square$ ) and CSF $(O)$ concentrations of thalidomide after oral administration of a $50 \mathrm{mg}$ dose 


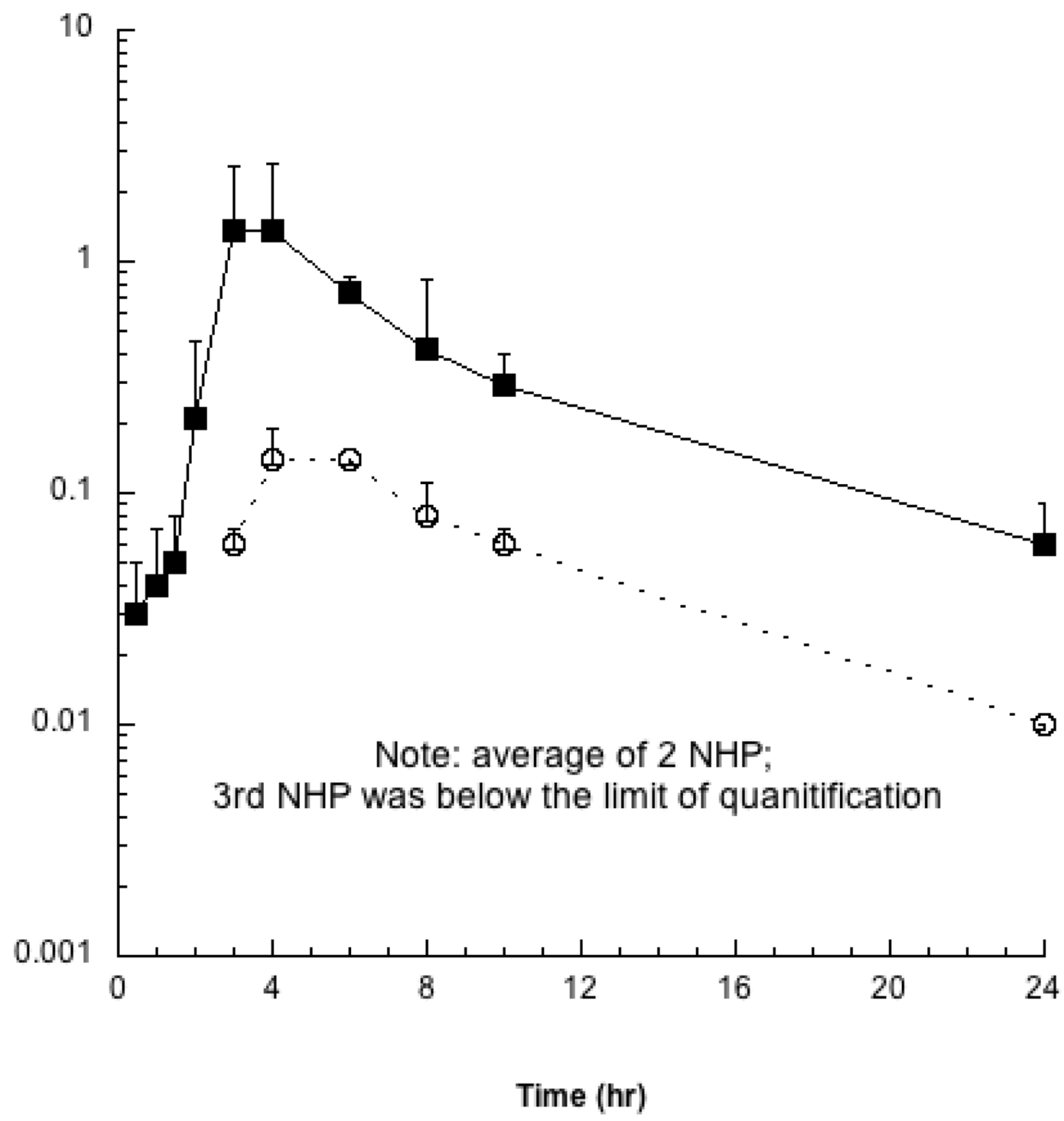

Fig. 2.

Mean plasma ( $\square$ ) and CSF $(\bigcirc)$ concentrations of lenalidomide after oral administration of a $20 \mathrm{mg}$ dose 


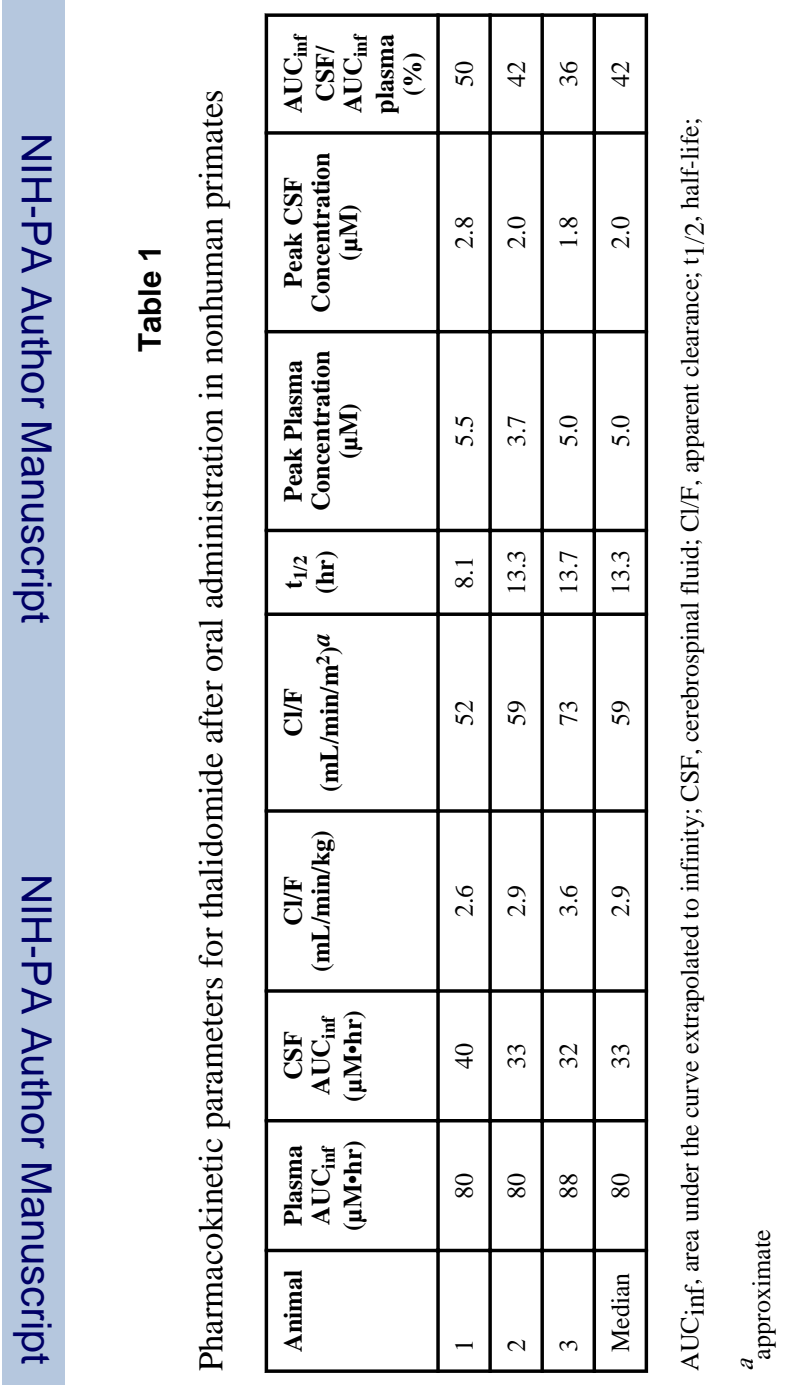

Cancer Chemother Pharmacol. Author manuscript; available in PMC 2013 June 18. 


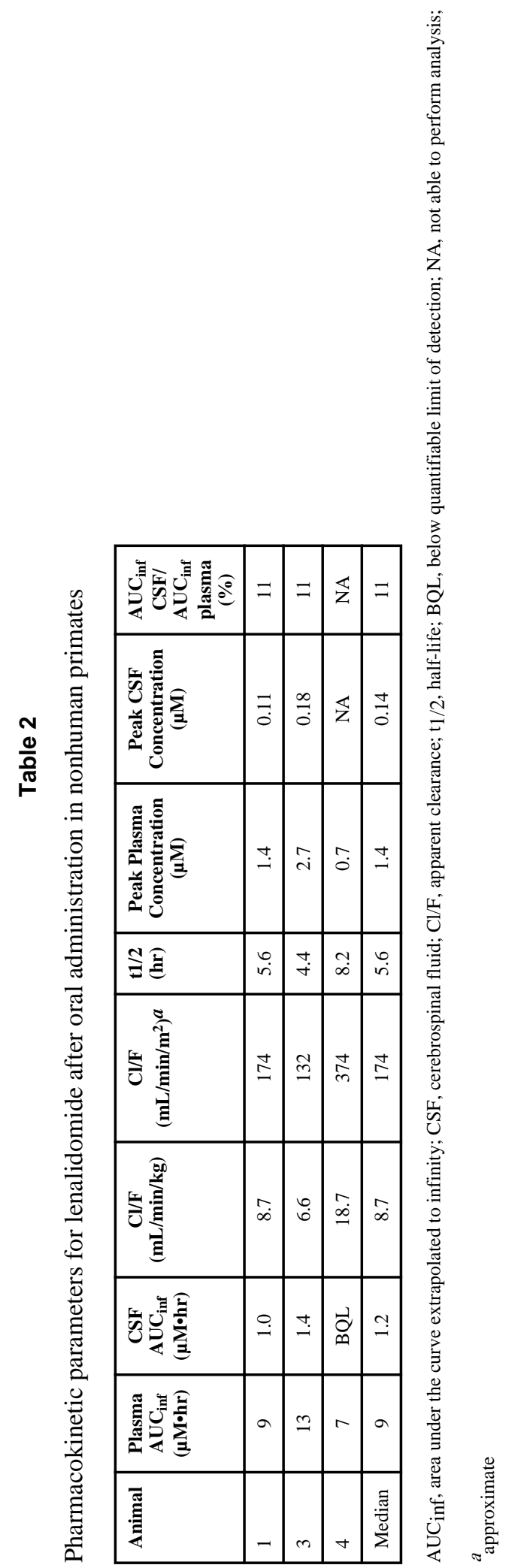

Cancer Chemother Pharmacol. Author manuscript; available in PMC 2013 June 18. 